\title{
INFLUENCE OF IMPURITIES ON THE ION-ION RECOMBINATION COEFFICIENTS IN OXYGEN GAS
}

K. Yamasaki and K. Katsurayama

Research Reactor Institute, Kyoto University Kumatori, 590-04

Abstract. This work was performed by means of the equilibrium method to clarify the correlation between the ion-ion recombination coefficients and the water vapor pressure of the oxygen gas. We obtained $1.486_{6} 10^{-6} \mathrm{~cm}^{3} / \mathrm{s}$ for the wet oxygen gas (dew point $0^{\circ} \mathrm{C}-15^{\circ} \mathrm{C}$ ) and $2.52 \times 10^{-6} \mathrm{~cm}^{3} / \mathrm{s}$ for the dry oxygen gas (dew point $-190^{\circ} \mathrm{C}$ ). The correlation between the average ion mass or the average hydration of the terminal ion clusters and the water vapor pressure of the oxygen gas was discussed and compared with Shahin's results which were obtained by the mass-spectrometric method.

\section{Introduction}

An ion which exists in the atmosphere is one of the important elements which affect upon the atmospheric phenomena. From the health phisical point of view, it seems that they affect upon the prosperity and decay of radioactive ions causing the inner exposure.

In the atmosphere, ions are produced mainly by some natural radiations (terrestrial gamma ray, cosmic ray, radon, thoron, etc). The ion density is determined by the balance of the production and the annihilation of the ions. The annihilation includes, (1) a recombination of positive ion and negative ion, (2) an attachment of ion to some aerosol particles and condensation nuclei.

The ion-ion recombination coefficient is closely concerned with an ionization equilibrium, a plateau characteristic of ionization chamber, a gaseous electronics and an ion chemistry in the upper atmosphere.

The recombination coefficient of small ions has been obtained by many investigators following Rutherford and Thomson. But there is a considerable discrepancy among their results. It seems that the discrepancy is caused by the impurities, especially, by the water vapor in the sample gas. It is expected that the water vapor molecules react with the ions in the sample gas to form a hydronium ion, and that the increase of the ion mass causes a decrease of the thermal drift velocity of the ion to lead the decrease of the recombination coefficient. But these correlations are not clear.

The objective of this paper is to clarify the correlation between the ion-ion recombination coefficient and the content of water vapor in the oxygen gas.

Several investigators have obtained, theoretically and experimentally, the recombination coefficient since the past century. Thomson's theory (1924) which is based on the three bodies impact is applied to the range of below one atmospheric pressure, and the recombination coefficient decreases with the atmospheric pressure decreases. Langevin-harper's theory (1932) which is based on the two bodies impact is applied to the range of above several atmospheric pressures, and the recombination coefficient decreases asymptotically with the atmospheric pressure increases. J. J. Thomson and Rutherford (1896) obtained experimentally, in the first place, the recombination coefficient from the plateau characteristic of an ionization chamber. Thereafter, several investigators clarified experimentally that the 
recombination coefficient had some characteristics depending on (1) the ion age, (2) the atmospheric pressure, (3) the temperature, (4) the ion density, etc. Gardner (1938) clarified by using the high vacuum technique that Thomson's theory has been exact at the tendency below atmospheric pressure, and obtained $(2.08 \pm 0.05) \times 10^{-6} \mathrm{~cm} / \mathrm{s}$ for the pure oxygen gas at atmospheric pressure. Sayers (1938) obtained independently by a same technique $2.3 \times 10^{-6} \mathrm{~cm} / \mathrm{s}$ for a dry air at atmospheric pressure. P. J. Nolan (1943) obtained $1.41 \times 10^{-6} \mathrm{~cm} / \mathrm{s}$, using the equilibrium method and growth method, in 3 the weakly ionized atmosphere. Ebert et al (1964) obtained 1.43 $\times 10^{-6}$ $\mathrm{cm}^{3} 6 \mathrm{~s}$ for the oxygen gas. MCGowan (1963, 1965. 1967) obtained (1.3 $\left.-\overline{6} 1.4 \frac{4}{3}\right) \mathrm{x}$ $10^{-6} \mathrm{~cm} / \mathrm{s}$ for the room air, and after obtained $(2.21 \pm 0.10) \times 10^{-6} \mathrm{~cm} / \mathrm{s}$ for the dry air.

Thus, there is a considerable amount of discrepancy among experimental values, and the value from Thomson's theory, for the oxygen gas at atmospheric pressure is $12.2 \times 10^{-6} \mathrm{~cm}^{3} / \mathrm{s}$. So we cannot say to have a satisfying value about ion-ion recombination coefficient.

2. Principle

When the gas in a vessel is irradiated by radiations, the ion density increases with the irradiation time as follows,

$$
N=(\alpha / q)^{1 / 2}\left[\exp \left\{2(\alpha q)^{1 / 2} t\right\}-1\right] /\left[\exp \left\{2(\alpha q)^{1 / 2} t\right\}+1\right]
$$

In this expression, $\mathrm{N}$ is the ion density, $\mathrm{q}$ the production rate of ion pairs, $\alpha$ the recombination coefficient, and $t$ the irradiation time. When the irradiation time goes long enough for the ion density to reach the equilibrium, the ion density reaches to the saturated equilibrium ion density indicated in a following formula,

$$
\mathrm{N}_{\text {eq }}=(\mathrm{q} / \alpha)^{1 / 2}
$$

Equilibrium method is a method which is able to get a recombination coefficient by measuring a production rate of ion pairs and a saturated equilibrium ion density,

\section{Experimental}

Figure 1 shows the arrangement of experimental apparatus. A parallelplate ionization chamber which was placed in a 200 liters vessel of stainless steel was used to measure a production rate of ion pairs and a saturated equilibrium ion density. The main chamber was constructed of stainless steel and the space of the collecting electrodes was $10 \mathrm{~cm}$, and its radius was $10 \mathrm{~cm}$ (the effective volume $832 \mathrm{~cm}$ ). A stainless steel guard ring having a width $10 \mathrm{~cm}$ was equipped to secure the effective volume. The current from the main chamber was measured by a vibrating reed electrometer. and recorded by a strip chart recorder.

To compensate a charging current induced on the electrometȩr by the collecting field, a dummy chamber ( the effective volume $10 \mathrm{~cm}$ ) was employed in the equilibrium bridge that the collecting fields $0.5 \mathrm{kV}$ of the opposite sign could be applied to the plates of both chambers. The dumm chamber was a parallel plate chamber which could change the space of the collecting electrodes.

Both condensers in the equilibrium bridge were coincided with the accuracy better than 0.1 percent. Two $10 \mathrm{M} \Omega$ steady resistances and a $1 \mathrm{M} \Omega$ variable resistance were used to coincide the potential supplying the both chambers. The charging current was minimized by varying the space of the 
collecting electrodes of the dummy chamber. Thus we could measure the saturated equilibrium ion density with the accuracy better than three percents.

The sample oxygen gas was ionized by the $88^{l l i m a t e d}$
beta rays from radiation source from the distance of $1 \mathrm{~m}$. The radiation source was contained in a polyethylene vessel and its outer side was shielded by the lead blocks. The acrylic pipe (inner radius $18 \mathrm{~mm}$, length $300 \mathrm{~mm}$ ) was used for the collimator. The vessel has a round window covered

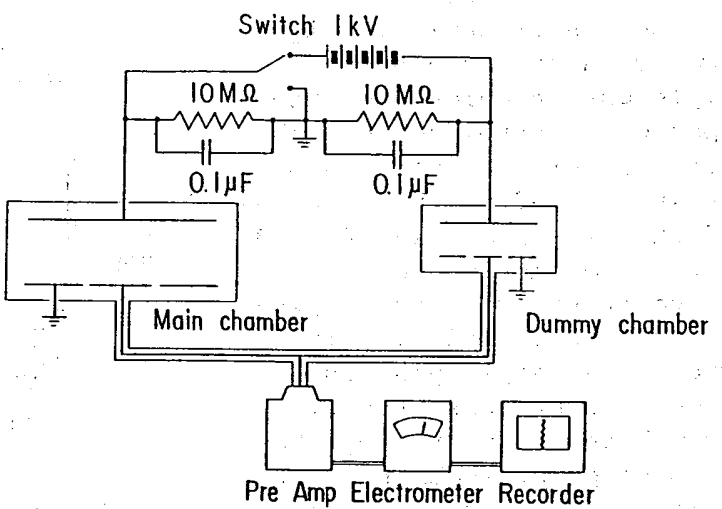

Fig.1. Arrangement of experimental apparatus. with the aluminized mylor (thickness $0.025 \mathrm{~mm}$ ), and this window was used to irradiate the sample oxygen gas in the main chamber. The main chamber was irradiated uniformly by the beta rays.

The production rate of the ion pairs was measured by the method of $a$ potential drop using a vibrating reed electrometer, and was determined as follows,

$$
q=i / e v
$$

where $q$ is production rate of ion pairs, $i$ ionization current, e the elementary charge, and $\mathrm{V}$ the effective volume of the main chamber.

The saturated equilibrium ion density was measured as follows,

(1) Start of the irradiation of the beta rays,

(2) Arrival to the saturated equilibrium ion density,

(3) "OPEN" of the vibrating reed electrometer,

(4) Apply the sweeping field (500 V) on the ionization chambers,

(5) Measure the collected charges by the method of charge accumulation.

Figure 2 shows a typical output from the electrometer due to the collected charges versus the elapsed time. The initial curve in this figure indicates the saturated equilibrium ion density, and the straight line indicates the production rate of ion pairs. The saturated equilibrium ion density was determined from the extrapolated value of the straight line versus the elapsed time $t=0$ as follows,

$$
\mathrm{N}_{\text {eq }}=\mathrm{C} \mathrm{x} / \mathrm{e} \mathrm{V}
$$

where $\mathrm{N}$ is the saturated equilibrium ion denstity, c the input capacitance of

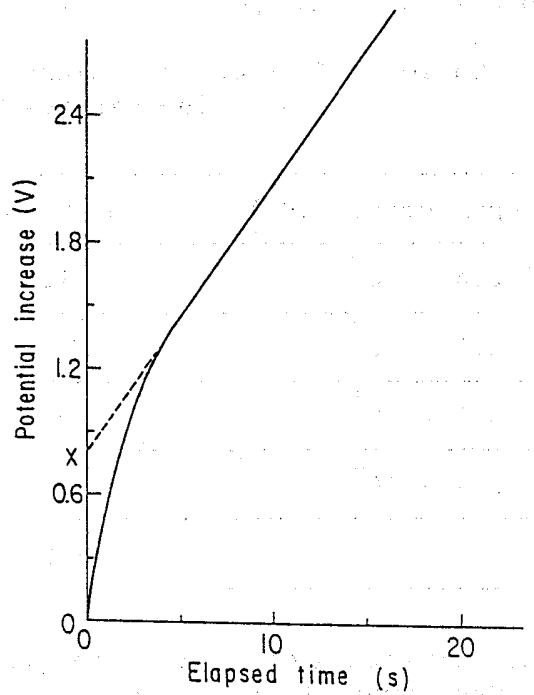

Fig.2. Typical output from the vibrating reed electrometer by the equilibrium method. 
the electrometer, and $\mathrm{x}$ the extrapolated value.

The system shown in Figure 3 was used to enclose the sample gas in which the water vapor was controlled into the main chamber. The main chamber was vacuumized to about $100 \mathrm{~Pa}$, and the oxygen gas was filled. up to atmospheric pressure. The water vapor in the oxygen gas was controlled by cold traps. The sample gas was circulated at least ten times through the cold trap by the enclosed pump. Membrane filter (pore size $0.3 \mu \mathrm{m}$ ) was set before and after the pump to

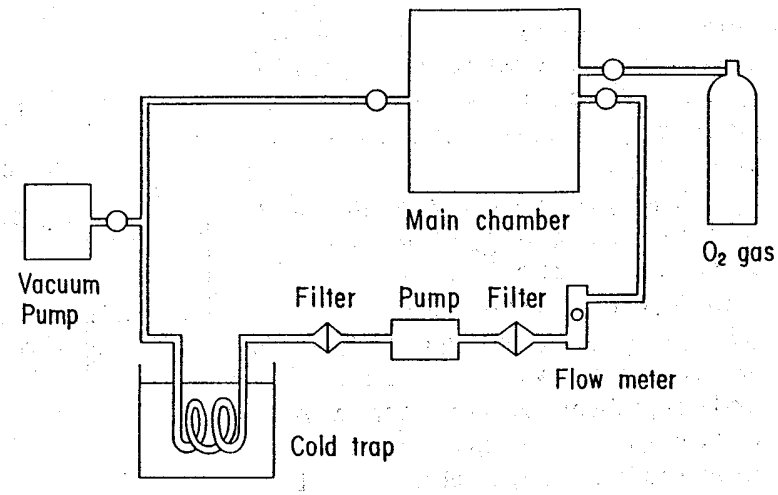

Fig.3. Control system of water vapor. remove the aerosol particles in the sample gas. Four types of cold traps were used, (1) a highly wet box, (2) a freezer and ethyleneglycol, (3) a dry ice and acetone, and (4) a liquid nitrogen. The water vapor pressures of the sample gas were measured by a Mcleod vacuum gauge using the liquid nitrogen cold trap in the cases of (1) and (2), and were evaluated from the correlations between the saturated water vapor pressure and the dew point in the cases of (3) and (4).

\section{Results and Discussion}

The experimental results of ion-ion recombination coefficients for the oxygen gas in which the water vapor was variously controlled are shown in Table 1 and Figure 4. Two series of the measurements were carried out to confirm the reproducibility. Each value in the No.1 and No.2 columns in the table is an average of thirty data. These results were obtained after the

Table 1. Ion-ion recombination coefficients in oxygen gas containing various water vapor

$$
\left(\times 10^{-6} \mathrm{~cm}^{3} / \mathrm{s}\right)
$$

\begin{tabular}{ccccc}
\hline Vapor press, $(\mathrm{Pa})$ & Dew point $\left({ }^{\circ} \mathrm{C}\right)$ & No.1 & No.2 & Average \\
\hline $2.4 \times 10^{3}$ & 15 & 1.49 & 1.47 & 1.48 \\
\hline $6.1 \times 10^{2}$ & 0 & 1.48 & 1.49 & 1.49 \\
\hline $8.7 \times 10^{1}$ & -22 & 1.78 & 1.92 & 1.85 \\
\hline $2.7 \times 10^{-1}$ & -77 & 2.33 & 2.29 & 2.31 \\
\hline 0 & -196 & 2.51 & 2.53 & 2.52 \\
\hline
\end{tabular}

same correction of a diffusion loss which was given by McGowan (1963).

The error of the effective volume of the main chamber is estimated to be 3 percents. The error of the input resistance of the vibrating reed electrometer is lower than 1 percent. The error of the extrapolation of the charge accumulation is about 3 percents. The error of the compensation of the 
charging current is about 3 percents. Therefore, the sum of errors is considered to be lower than 10 percents.

Table 2. Classified ion-ion recombination coefficients according to the difference of water vapor in sample gases

$$
\left(\mathrm{x} 10^{-6} \mathrm{~cm}^{3} / \mathrm{s}\right)
$$

\begin{tabular}{|c|c|c|c|c|c|}
\hline Name & Fiscal year & Sample gas & Dry & & Wet \\
\hline M. E. Gardner & 1938 & $\mathrm{O}_{2}$ & $2.08 \pm 0.05$ & . & \\
\hline S. Sayers & 1938 & Air & 2.3 & i & $\because$ \\
\hline P. J. Nolan & 1943 & Air & & & 1.41 \\
\hline Ebert et al & 1964 & $\mathrm{O}_{2}$ & & 1.43 & . \\
\hline S. McGowan & 1965 & Air & & & $1.3-1.4$ \\
\hline S. McGowan & 1967 & Air & $2.21 \pm 0.10$ & & $\therefore$ \\
\hline Present work & 1986 & $\mathrm{O}_{2}$ & 2.52 & & 1.48 \\
\hline
\end{tabular}

The experimental results of ion-ion recombination coefficient obtained by many researchers since 1938 are summarized and classified into dry or wet sample gases in Table 2. It shows that the values for dry gases are large $\left(2.0-62.5 \times 10^{-6} \mathrm{~cm}^{3} / \mathrm{s}\right)$ and the values for wet gases are small $(1.3-1.5$ $\left.\times 10^{-6} \mathrm{~cm}^{3} / \mathrm{s}\right)$.

Figure 4 shows that the ion-ion recombinatin coefficient changes greatly between the dew point range of $10^{\circ} \mathrm{C}$ and $-77^{\circ} \mathrm{C}$.

From these results, it is considered that the discrepancy among various values of recombination coefficient is concerned with the tracer elements, especially, with the water vapor in the sample gas. It suggests that the ionion recombination coefficient depends on the change of the ion mass which is caused by the reactions between the ions and water

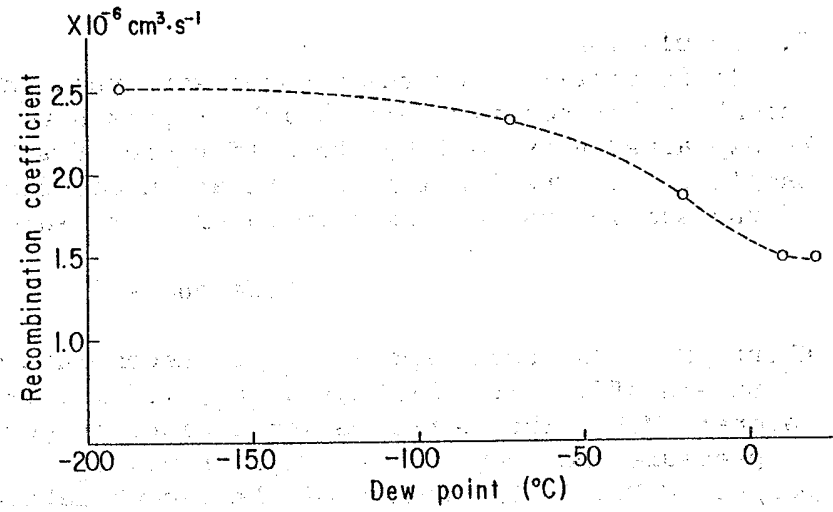

Fig. 4. Correlation between the ion-ion recombination coefficients and dew points of oxygen gas.

vapor molecules in the oxygen gas.

Indeed, it is known from Thomson's theory that the ion-ion recombination coefficient is inversely proportional to the root of the average ion mass. Therefore, the average ion mass for the wet oxygen gas is estimated to be about 2.89 times larger than that for the dry oxygen gas from the ion-ion recombination coefficients in this work. It is well known that the terminal ions are $\mathrm{O}_{2}^{+}, \mathrm{O}_{4}^{+}, \mathrm{O}_{2}^{-}$, and $\mathrm{O}_{4}^{-}$, when the water vapor does not exist in the 
oxygen gas. From Voshall et al (1965), $\left[\mathrm{O}_{2}^{-}\right]$is sixth times more than $\left[\mathrm{O}_{4}^{-}\right]$, and $\left[\mathrm{O}_{4}^{+}\right]>>\left[\mathrm{O}_{2}^{+}\right]$in dry oxygen gas at the atmospheric pressure and $300 \mathrm{H}_{\mathrm{K}}$. Therefore, the average ion mass is estimated to be about 50 amu from their masses in the dry oxygen gas. On the other hand, the ions which exist in the wet oxygen gas react with the water vapor molecules to form the hydrated terminal ion clusters of $\left(\mathrm{H}_{3} \mathrm{O}^{+}\right) \cdot\left(\mathrm{H}_{2} \mathrm{O}\right)$ or $\mathrm{O}_{2}$. $\left(\mathrm{H}^{3} \mathrm{O}\right)$ by ${ }^{2}$ Mohnen $(1969,1970)$, and the hydration depends on the water vapor in the oxygen gas. Figure 5 : shows the correlation between the dew point of the oxygen gas and the average ion mass or its hydration which are converted from the ion-ion recombination coefficients. In this figure, Shahin's data (1966) was obtained using a mass spectrometric method for the

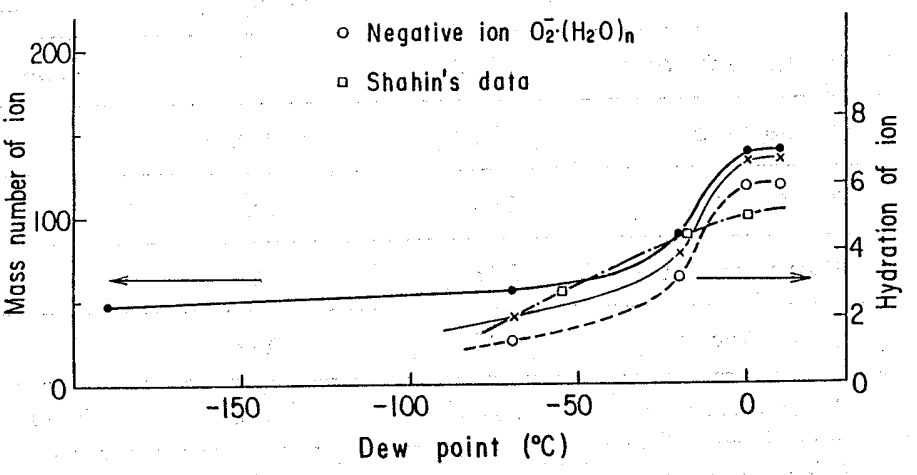

Fig. 5. Correlation between the dew point of the oxygen gas and the average ion mass or its hydration. positive ions in the oxygen gas. Present data depend on the water vapor pressure more than the Shahin's data, but both data indicate to be in good accordance on the tendency in spite of the different experimental methods.

\section{Conclusion}

It is clarified by the present work that the discrepancy of the ion-ion recombination coefficients, which origins have not been known till now, can be explained very well by the difference of water vapor pressures in the sample gases. The ion-ion recombination coefficient depends on the conditions of the sample gas such as temperature, pressure and humidity.

\section{References}

Ebert, H.G., J. Booz, and R. Koepp, Recombination von Ionen in Luft und Sauerstoff, Zeits. fur Phys., 181, 187-195,1964.

Gardner, M.E., The recombination of ions in pure oxygen as a function of pressure and temperature, Phys. Rev., 53, 75-83, 1938.

Harper, W.R., On the theory of the recombination of ions in gases at high presures, Proc. Camb. Phil. Soc., 28, 219-233, 1932.

McGowan, S., Ion-ion recombination and ion mobility measurements in laboratory air, D.C.B.R. Report, No. 410, 1963.

McGowan, S., Ion-ion recombination in laboratory air, Phys. Med. Biol., 10, $25-41,1965$.

McGowan, S., Ion-ion recombination coefficient, Canad. Journ. Phys., $\underline{45}$, $439-448,1967$.

Mohnen, V.A., on the nature of tropospheric ions, Planetary Electrodynamics, S. C. Coroniti and J. Hughes, eds, Gordon and Breach, New York, 197-230, 1969.

Mohnen, V.A., Preliminary results on the formation of negative small ions in the troposphere, Journ. Geophys. Res., 75, 1717-1721, 1970. 
Nolan, P.J., The recombination law for weak ionization, Proc. Roy. Irish. Acad., 49, 67-90, 1943.

Sayers, J., Ionic recombination in air, Proc. Roy. Soc., Al69, 83-101, 1938.

Shahin, M.M., Mass-spectrometric studies of corona discharges in air at atmospheric pressures, Journ. Chem. Phys., 45, 2600-2605, 1966.

Thomson, J.J., Recombination of gaseous ions, the chemical combination of gases, and monomolecular reactions, Phil. Mag., 47, 337-378, 1924.

Thomson, J.J. and E. Rutherford, On the passage of electricity through gases exposed to Rontgen rays, Phil. Mag., 42, 392-407, 1896.

Voshall, R.E., J.L. Pack and A.V. Phelps, Mobility of negative ions in $\mathrm{O}_{2}$ at low E/N, Journ. Chem. Phys., 43, 1990-1995, 1965.

(Received April 25, 1986;

revised June 18, 1986;

accepted June 30, 1986.) 